\title{
Fluorescently-tagged polyamines for the staining of siliceous materials
}

Vadim V. Annenkov ${ }^{a, k}$, Elena N. Danilovtsevaa ${ }^{a}$, Viktor A. Pal'shina, Olga N.

Verkhozina ${ }^{a}$, Tatyana A. Shishlyannikova ${ }^{a}$, Graham J. Hickman ${ }^{b}$, Carole C. Perry ${ }^{b}$

aLimnological Institute Siberian Branch of the Russian Academy of Sciences, 3,

Ulan-Bator Str., Irkutsk, 664033, Russia

${ }^{b}$ Interdisciplinary Biomedical Research Centre, Nottingham Trent University, Clifton

Lane, Nottingham, NG11 8NS, UK

${ }^{*}$ Corresponding author. E-mail address: annenkov@lin.irk.ru (V. Annenkov)

\section{Abstract}

Siliceous frustules of diatom algae contain unique long-chain polyamines, including those having more than six nitrogen atoms. These polyamines participate in the formation of the siliceous frustules of the diatoms but their precise physiological role is not clear. The main hypotheses include formation of a polyamine and polyphosphate supramolecular matrix. We have synthesized novel fluorescent dyes from a synthetic oligomeric mixture of polyamines and the fluorophore 7-nitro-2,1,3-benzoxadiazole. The long polyamine chain ensures the high affinity of these dyes to silica, which allows their application in the staining of siliceous materials, such as valves of diatom algae and fossilized samples from sediments. The fluorescently stained diatom valves were found to be promising liquid flow tracers in hydrodynamic tests. Furthermore, complexation of the polyamine component of the dyes 
with carbonic polymeric acids results in changes to the visible spectrum of the fluorophore, which allows study of the stability of the complex vs the length of the polyamine chain. Using poly (vinyl phosphonic acid) as a model for phosphate functionality in silaffins (a potential matrix in the formation of biogenic silica) little complexation with the polyamine fluorophores was observed, bringing into question the role of a polyamine - polymeric phosphate matrix in biosilicification.

\section{Keywords}

NBD-Cl; fluorescent dye; polyamine; diatom algae; HPLC; polyacid

\section{Introduction}

Diatom algae play an important role in silicon and carbon cycles and they are among the main oxygen sources on the Earth (Treguer et al., 1995; Armbrust, 2009). Diatoms are also important components of freshwater lakes, where they comprise a large portion of the total algal biomass (Stevenson et al., 1996). Diatom cells live in siliceous frustules, which are unique constructions formed from nearly anhydrous silicon dioxide (Grachev et al., 2008). The frustules are punctuated with submicrometer pores (Fig. 1). The frustule shape and the arrangement of the pores are species-specific. The siliceous frustules of diatoms have been applied industrially as sorbents, filtration elements and as plastic fillers (Dolatabadi and de la Guardia, 2011; Parkinson and Gordon, 1999). The unique morphology of the frustules allows them to be used as UV filters (Su et. al, 2018) and in photonic applications (Su et. al, 2015). The structure and nature of the diatom silica provides incentives for the elaboration of bioinspired materials and processes (Dolatabadi and de la Guardia, 2011; Gordon et al., 2009; Townley et al., 2008; Rosi et al. 2004). Specific fluorescent dyes are a powerful instrument in study of silicification 
mechanisms in vitro and in vivo (Parambath et al., 2016 and references in this article). Molecules of these dyes contain basic moieties which provides an affinity to acidic silicon containing vesicles. Study of the molecular mechanisms of diatom silica formation resulted in the isolation of polyamines containing seven or more nitrogen atoms in the chain (Sumper et al., 2005; Sumper and Kroger, 2004). Previously we have elaborated a step-wise method for synthesis of short-chain ( $\leq 7$ nitrogens) polyamines, which are structurally similar to biogenic polyamines (Annenkov et al., 2006). Condensation of short-chain polyamines with 1,3-dibrompropane gives rise to long-chain polyamines (LCPA, Fig. 2) (Annenkov et al., 2009). Fluorescent derivatives of short-chain polyamines were obtained by reaction with 4-chloro-7-nitro-2,1,3benzoxadiazole (NBD-Cl) (Annenkov et al., 2010; Danilovtseva et al., 2013) and these substances were used in the study of the biosilicification mechanism (Annenkov et al., 2014). NBD-tagged polyamines containing 4 or 5 nitrogen atoms were used for the staining of diatom frustules in addition to the spicules of siliceous sponges (Annenkov et al., 2015). Diatom frustules and sponge spicules consist of transparent material which complicates study of these objects by light microscopy. Fluorescent staining of siliceous diatom frustules as well as staining of various siliceous and composite materials permits increased resolution in microscopy studies and to subsequently obtain high quality images, including 3D reconstructions, with confocal microscopy (Friedrichs, 2013; Shimizu et al., 2001; Desclés et al. 2008). Silica and many valuable minerals, e.g. zeolites, bear acidic surface groups, which allow staining with dyes containing basic functional groups. Interaction between polymeric acids and bases is enhanced with increase in the number of interacting groups and we can expect increased stain performance in the case of dyes based on LCPA. Fluorescent-tagged LCPA are also interesting as a tool for the study of 
various polyamine properties, including equilibrium interactions with polymeric acids and the physiological role of polyamines in living organisms (e.g. diatoms, sponges).
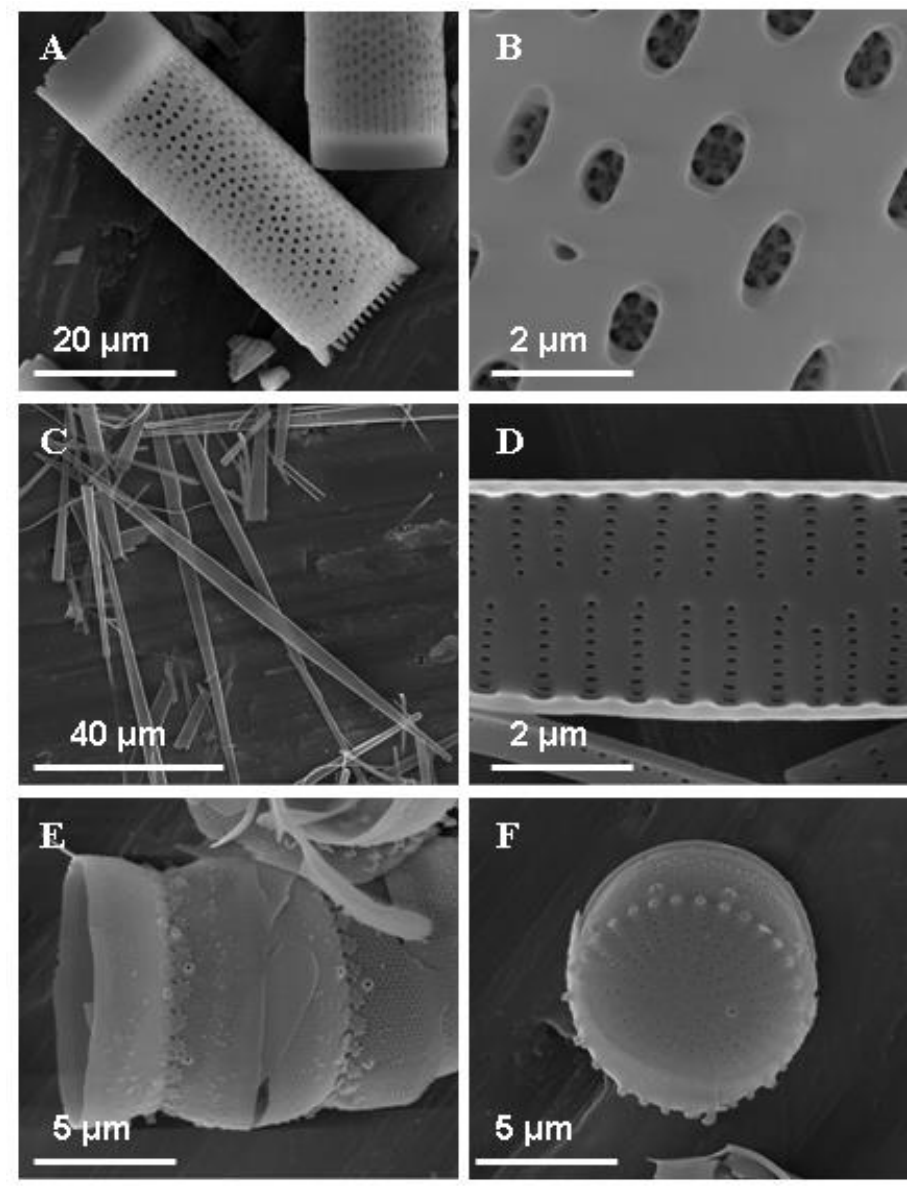

Figure 1. Scanning electron images of siliceous diatom valves. Aulacoseira Sp. (A) and (B); Ulnaria ferefusiformis Kulikovskiy (C) and (D), Stephanodiscus meyerii Genkal et Popovsk. (E) and (F).

This article describes the synthesis of NBD-tagged LCPA containing more than six nitrogen atoms. A mixture of LCPA oligomers was modified by the action of $\mathrm{NBD}-\mathrm{Cl}$ and the obtained dye was applied to the staining of diatom frustules and other materials. Chromatographic separation allowed individual fluorescent polyamines to be obtained which are promising substances for the study of LCPA biochemistry. Fluorescent polyamines with polyamine chains of varying length were further used to study the interactions between polymeric acids and polyamines. 


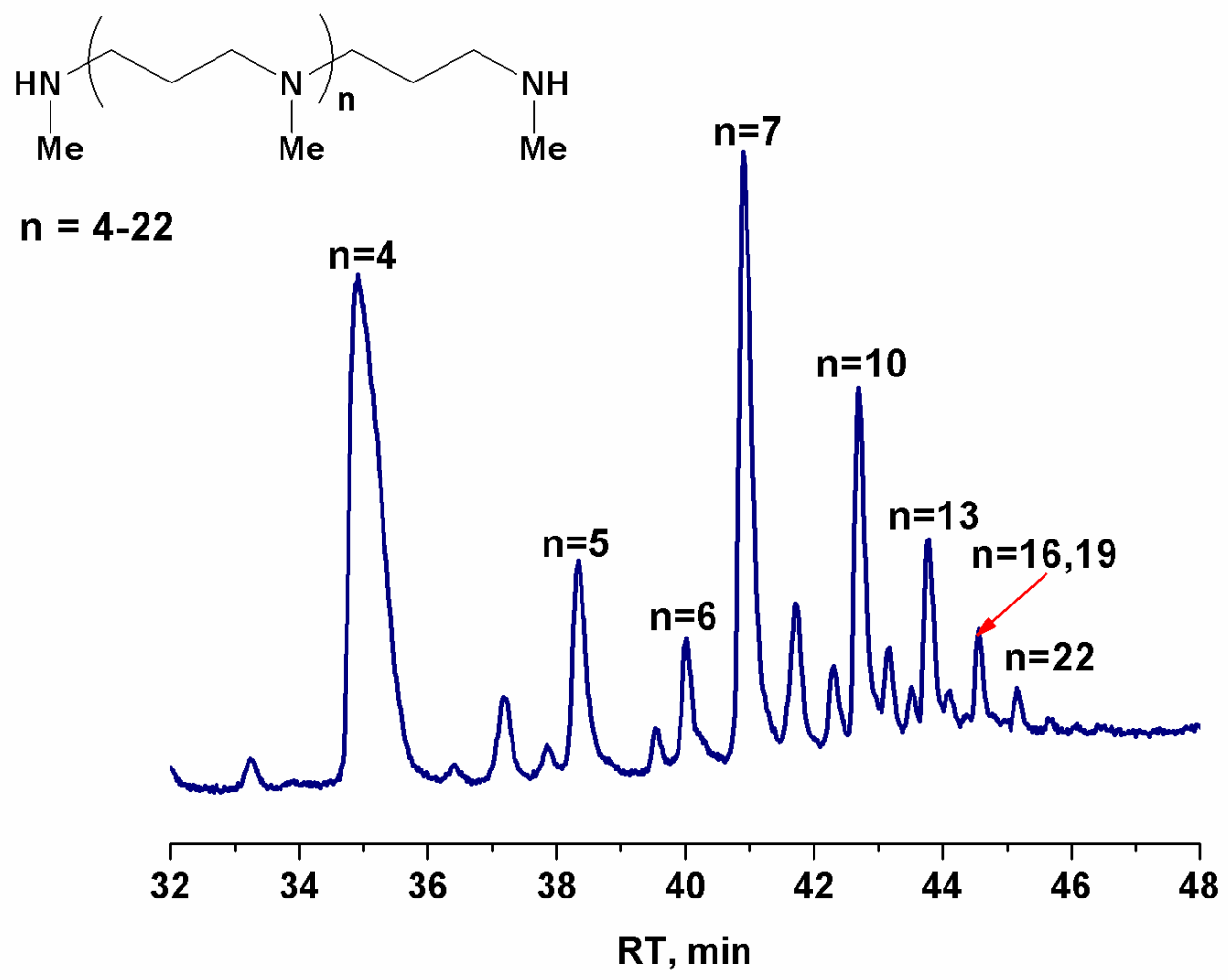

Figure 2. Chromatographic separation of a mixture of polypropylamine synthetic analogs of natural LCPA. HFBA was used as an ion-pairing reagent.

\section{Materials and Methods}

\section{Reagents}

The initial LCPA mixture was prepared according to the previously published method (Annenkov et al., 2006). NBD-Cl was purchased from Alfa Aesar (99\% purity). Silica gel Panreac $60(63-200 \mu \mathrm{m})$ was used for flash chromatography. Acetonitrile, methanol, water - HPLC grade. Ether, dichloromethane, potassium carbonate, ammonium hydroxide, HFBA (heptafluorobutyric acid), TFA (trifluoroacetic acid) acids were of reagent grade (Sigma-Aldrich, Fisher, or Acros). Acryloyl and methacryloyl chlorides (SigmaAldrich) were distilled before use. Vinylphosphonic acid (Sigma-Aldrich) was purified according to (Millaruelo et. al., 2008). 
Poly(acrylic acid) (PAA) and poly(methacrylic acid) (PMAA) were obtained similarly to the procedure described earlier, (Buruiana et al., 2007) by polymerization of acryloyl or methacryloyl chloride $(5 \mathrm{~g})$ in $20 \mathrm{~mL}$ of dioxane with the addition of $0.1 \mathrm{~g}$ AIBN in argon atmosphere at $60{ }^{\circ} \mathrm{C}$ for $48 \mathrm{~h}$. The obtained polymer was poured into water $(50 \mathrm{~mL})$ and dialyzed against water. After freeze drying, PAA and PMAA were obtained with 90 and $82 \%$ yield respectively. According to viscometry data, (Newman et al., 1954) molecular weight was $15.6 \mathrm{kDa}$ for PAA and $20.1 \mathrm{kDa}$ for PMAA. Poly(vinylphosphonic acid) (PVPA) was synthesized according to (Millaruelo et. al., 2008) by polymerization of the corresponding monomer in conditions which generate polymers with $40 \mathrm{kDa}$ molecular weight.

\section{Instrumentation}

\section{$\underline{\mathrm{HPLC} \text { and mass-spectrometry }}$}

Analytical HPLC was performed with a Zorbax 300 SB-C18 chromatographic column $(2.1 \times 150 \mathrm{~mm}, 5 \mu \mathrm{m})$ at $35^{\circ} \mathrm{C}$, with flow rate of 0.2 $\mathrm{mL} / \mathrm{min}$. The injection volume of sample solution was $2 \mu \mathrm{L}$, water and acetonitrile with $0.1 \%(\mathrm{v} / \mathrm{v})$ HFBA were used as eluting solvents $A$ and $B$ respectively. A gradient from $10 \% \mathrm{~B}$ to $30 \% \mathrm{~B}$ for $30 \mathrm{~min}$, then to $60 \% \mathrm{~B}$ for 15 min, and to $100 \%$ B for 1 min, after that 10 min $100 \%$ B was used. NBD-LCPA narrow fractions and individual compounds were collected by preparative HPLC (DIONEX, semi-prep column Phenomenex $9.4 \times 250$ mm, $5 \mu \mathrm{m}$, RP C18 Zorbax $300 \mathrm{SB}$ ), flow rate $2 \mathrm{~mL} / \mathrm{min}$, injection volume $200 \mu \mathrm{L}$, sample concentration $10 \mathrm{mg} / \mathrm{mL}$ and the same eluting solvents and gradient were applied. A TFA-based eluent was also used for some samples. UV detection was applied at $350 \mathrm{~nm}$.

Mass-spectrometry was carried out with MALDI or ESI systems. An Agilent 1200 chromatographic system controlled by Chemstation Version 
B.01.03 (Agilent Technologies, USA) coupled to Agilent MSD-TOF 6210 with an ESI source operated in the positive mode was used for analysis of NBD-LCPA mixtures. The main parameters were: capillary voltage $3500 \mathrm{~V}$, nebulizer gas $\left(\mathrm{N}_{2}\right)$ at $45 \mathrm{psi}$, drying gas $\left(\mathrm{N}_{2}\right)$ at $5 \mathrm{~L} / \mathrm{min}$, desolvation temp $350^{\circ} \mathrm{C}$, scan range $\mathrm{m} / \mathrm{z}$ 100-2500. Fractions were analyzed using a Bruker ultrafleXtreme MALDITOF-TOF mass spectrometer. Operated in positive ion mode over an $\mathrm{m} / \mathrm{z}$ range (with matrix suppression) of 650-4000. Samples aliquots of $1.0 \mu \mathrm{L}$ were dispensed to a Bruker 384 position ground steel target with $1.0 \mu \mathrm{L}$ of 5.0 $\mathrm{mg} / \mathrm{mL}$ CHCA matrix, 50\% acetonitrile, $0.1 \%$ TFA and were analyzed immediately once dry.

Fluorescent microscopy was performed using an inverted microscope Motic AE-31T with a mercury lamp HBO 103 W/2 OSRAM. Excitation was at $470 \mathrm{~nm}$, and emission was observed above $515 \mathrm{~nm}$.

Confocal images were obtained using a Zeiss LSM710 microscope with the following parameters: excitation $488 \mathrm{~nm}$; detector slit 501 to $572 \mathrm{~nm}$ with a $\times 63$ oil immersion objective. Samples were immersed in a $1 \%$ agar solution.

Scanning electron microscopy (SEM) was performed using a FEI Quanta 200. The samples were dispersed in hexane and drops of the dispersion were placed on aluminum sample holders, allowed to dry and then sputter coated with gold using an SDC 004 (BALZERS) coater.

\section{Synthesis of NBD-LCPA dye}

A solution of $0.5 \mathrm{~g}(2.5 \mathrm{mmol})$ of $\mathrm{NBD}-\mathrm{Cl}$ in $50 \mathrm{~mL}$ of ether was added dropwise to a solution of $1 \mathrm{~g}$ (1.67 mmol, calculating as N9) of LCPA mixture in $50 \mathrm{~mL}$ of ether cooled to $4^{\circ} \mathrm{C}$ with stirring in an ice bath in an argon atmosphere. The resulting dark brown mixture was stirred in an ice bath for 4 $\mathrm{h}$, then $3 \mathrm{~h}$ at room temperature. After this time, the volatiles were removed under aspirator vacuum while keeping the bath temperature near $25^{\circ} \mathrm{C}$. The 
residue was thoroughly mixed with $1 \mathrm{~mL}$ of an aqueous solution of $\mathrm{K}_{2} \mathrm{CO}_{3}(50 \%$, $\mathrm{w} / \mathrm{w})$ and extracted with dichloromethane $(6 \times 5 \mathrm{~mL})$. The combined extracts were dried with anhydrous potassium carbonate and filtered. The filtrate was evaporated to dryness. The dark viscous mass was separated into 4 fractions by flash chromatography on $\mathrm{SiO}_{2}$ (particle size $15-40 \mu \mathrm{m}$ solvent system $\mathrm{CH}_{2} \mathrm{Cl}_{2}$ /ethanol/ammonia 9/4/1 v/v). Each fraction was analyzed by HPLC-MS (Agilent 6210 TOF LC/MS), and then each of the 4 fractions was separated by semi-preparative HPLC to give several peaks. Material from the main peaks was collected several times from multiple injections under the same conditions using the semi-preparative column, concentrated and analyzed by MALDI TOF.

\section{Sediment samples and siliceous diatom frustules}

A sample of sediment was collected from Lake Baikal (Russia) (VER-12-3 St13GC1 core, taken on 22 July 2012 at 233 m depth, coordinates

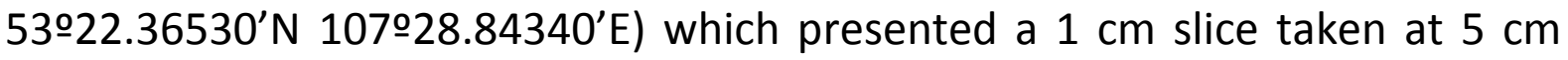
from the bottom. Natural samples of the freshwater diatoms Aulacoseira Sp., Cyclotella sp. and Stephanodiscus meyerii Genkal et Popovsk. obtained from Lake Baikal were also used. A clonal culture of the diatom Ulnaria ferefusiformis Kulikovskiy, Lange-Bertalot (Kulikovskiy et al., 2016) was isolated from phytoplankton of Lake Baikal, Listvennichny Bay, Russia. The diatom $U$. ferefusiformis was cultivated in DM medium (Thompson et al., 1988).

A suspension of living diatom cells was centrifuged (3000 g, $10 \mathrm{~min}$ ), washed twice with water, and the precipitate dried under vacuum $(0.2 \mathrm{~mm} \mathrm{Hg}$, room temperature, $48 \mathrm{~h}$ ). The cells were washed with a dichloromethane / isopropanol mixture $(1: 1, \mathrm{v} / \mathrm{v})$ five times to remove organic substances. The product was added to $\mathrm{H}_{2} \mathrm{O}_{2}$ solution $(30 \%, 5 \mathrm{~mL})$, and concentrated sulfuric acid ( $5 \mathrm{~mL}$ ) added cautiously to the $\mathrm{H}_{2} \mathrm{O}_{2}$ suspension under agitation and 
cooling with cold water $\left(4-8^{\circ} \mathrm{C}\right)$. The mixture was kept for $24 \mathrm{~h}$ at room temperature, diluted with water $(10 \mathrm{~mL})$, and centrifuged $(2800 \mathrm{~g}, 10 \mathrm{~min})$. Then, the precipitate was washed with water $(15 \mathrm{~mL}$, six times), ammonia water $(0.034 \%, 15 \mathrm{~mL})$, water $(25 \mathrm{~mL})$, and acetone $(25 \mathrm{~mL})$. The precipitate was dried under reduced pressure.

The obtained siliceous samples were stained with corresponding solutions of the NBD-tagged polyamines by vortexing during $2 \mathrm{~h}$ followed by washing with an excess of water (five times), the stained precipitates were centrifuged after each washing $(2800 \mathrm{~g}, 10 \mathrm{~min})$.

\section{Results and discussion}

\section{Synthesis of NBD-tagged polyamines}

NBD-tagged polyamines were obtained by the reaction of an oligomeric LCPA mixture with NBD-Cl similar to (Annenkov et al., 2010):
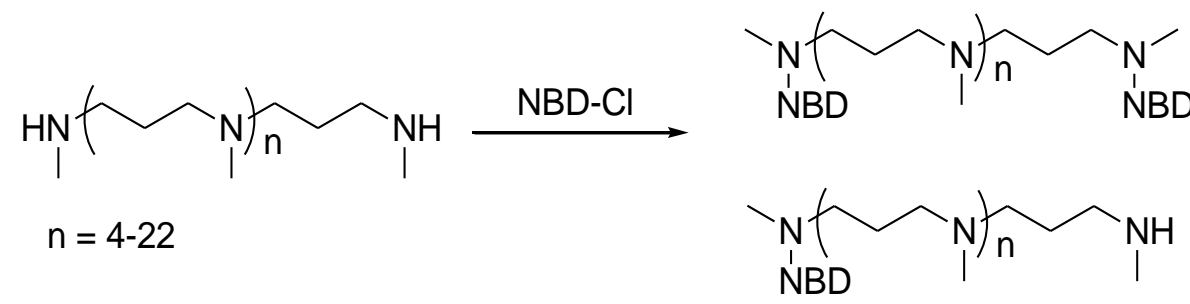

The obtained product was separated into four fractions with the use of flash chromatography and the fractions were analyzed with HPLC-MS and MALDI. Eluents for HPLC contained HFBA or cheaper TFA as an ion-pairing agent (Hakkinen et al., 2007; Bridoux and Ingalls, 2010). The first fraction contains mainly polyamines with two NBD moieties (Fig 3). Chromatographic data shows the presence of $67.6 \mathrm{~mol} \%$ of $\mathrm{N} 9$ and longer NBD-tagged LCPA. The second fraction (Figure 4) contains $81.1 \mathrm{~mol} \%$ of singly tagged LCPA (N6 N18). The third fraction is enriched with NBD-N12NH (Fig. 5). The fourth 
fraction contains mono- and disubstituted polyamines in approximately equal amounts (Fig. 6). Generally, the flash chromatography did not enable individual NBD-tagged polyamines to be obtained but allowed the dye to be purified from short-chain molecules that are formed due to cleavage of the polyamine chain in the reaction with NBD-Cl (Annenkov et al., 2015). Preparative isolation of the NBD-tagged polyamines was done with preparative HPLC in $0.1 \%$ TFA and resulted in several mg of pure samples 2NBD-N6, 2NBD-N9, 2NBD-N12, NBD-N9NH, NBD-N12NH, and a mixture of long polyamines 2NBD-N15 and 2NBD-N18. MALDI spectra of the individual NBD-tagged polyamines are presented in Table S1 in the Supplementary Material.

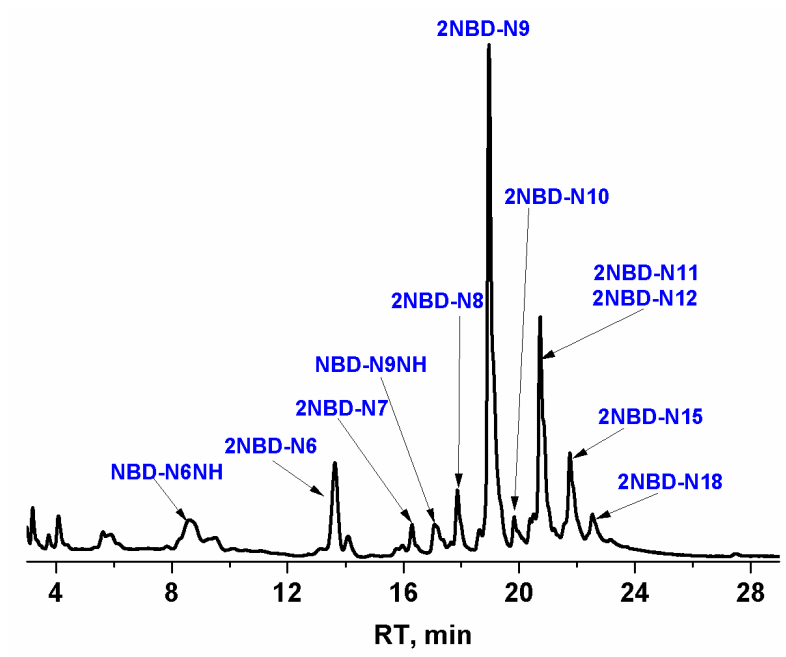

Figure 3. HPLC of the first NBD-LCPA fraction (HFBA-based eluent).

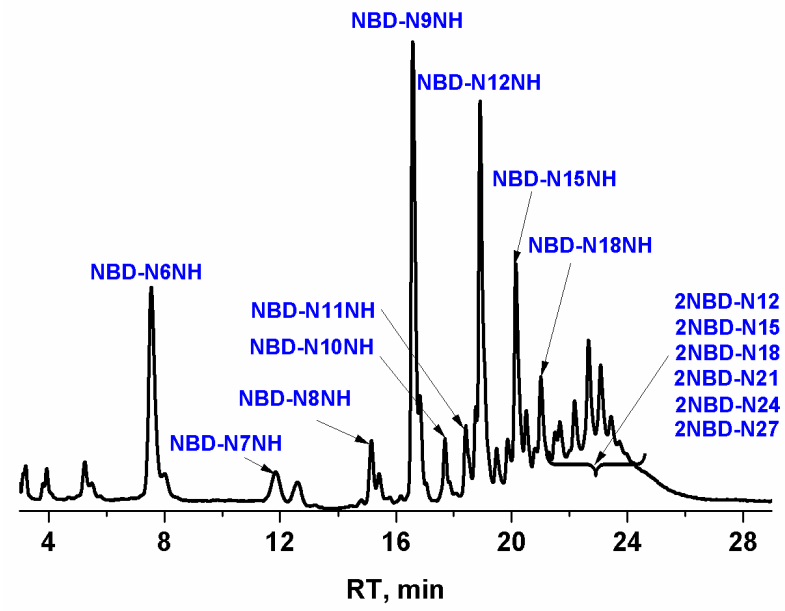

Figure 4. HPLC of the second NBD-LCPA fraction (HFBA-based eluent). 


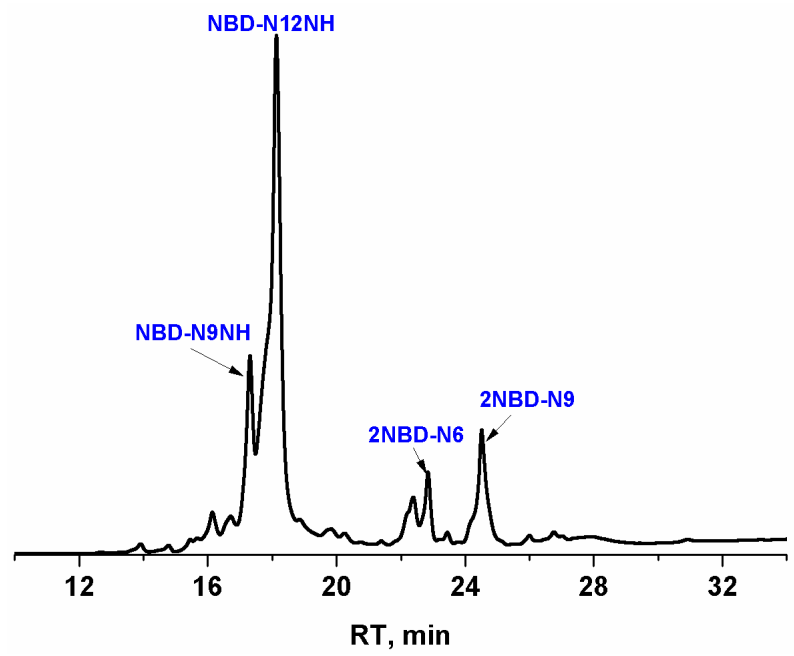

Figure 5. HPLC of the third NBD-LCPA fraction (TFA-based eluent).

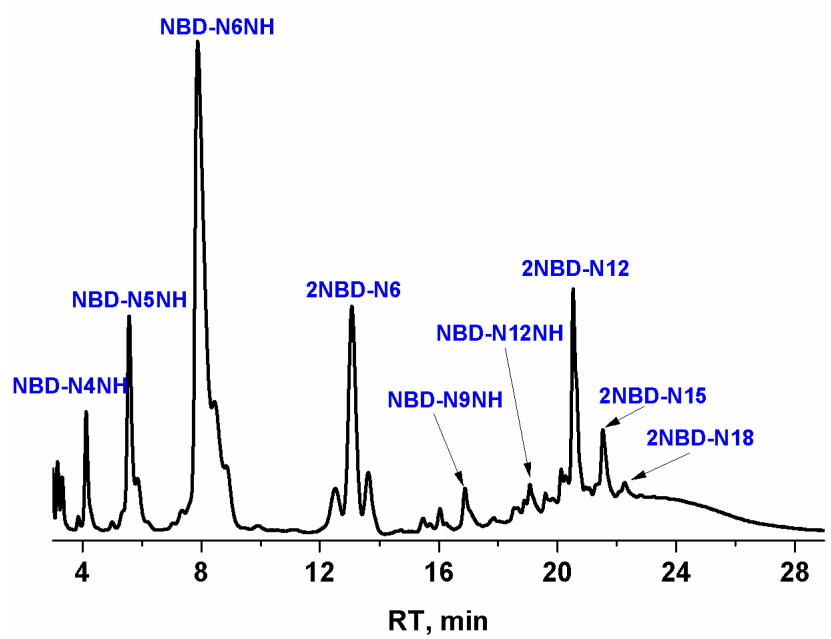

Figure 6. HPLC of the fourth NBD-LCPA fraction (HFBA-based eluent).

\section{Staining of siliceous diatom frustules with NBD-tagged polyamines}

The previously obtained dye NBD-N5NH (Annenkov et al., 2015) was used to determine an optimal concentration for the staining of diatom frustules (Fig. 7) and a $2 \mu \mathrm{M}$ concentration was chosen for further work. NBDN3, NBD-N5NH, 2NBD-N5 and three fractions of NBD-LCPA were compared following staining of the diatom frustules (Fig. 8). The obtained results show considerably higher staining activity of the NBD tagged LCPA, which is explainable due to the higher affinity of long polyamine chains to silica (Belton et al., 2008). 


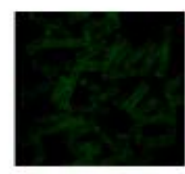

A

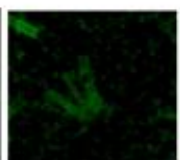

B

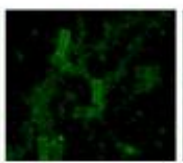

C

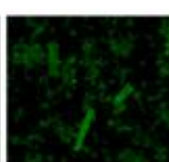

D

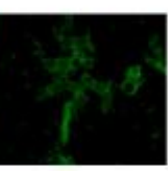

$\mathbf{E}$

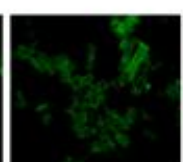

$\mathbf{F}$

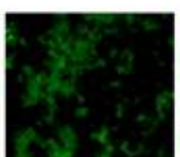

G

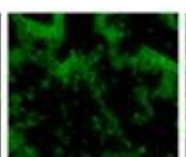

H

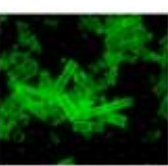

J

Figure 7. Siliceous frustules of Aulacoseira Sp. stained with NBD-N5NH. The dye concentration was: A - 0.1, B - 0.5, C - 1, D - 2, E - 5, F - 10, G - 20, H - 50, J -100 $\mu \mathrm{M}$.

A

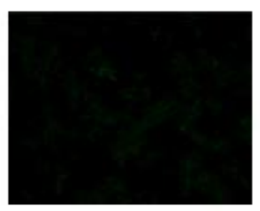

B

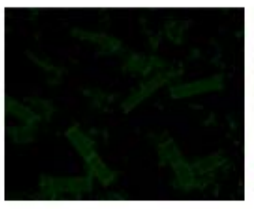

C

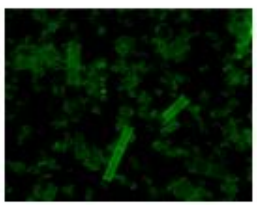

D

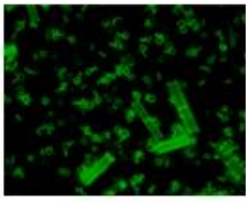

E

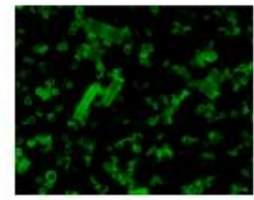

$\mathbf{F}$

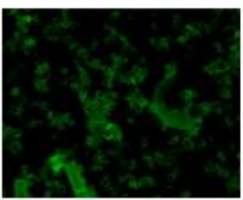

Figure 8. Staining of siliceous frustules of Aulacoseira Sp. with NBD-based dyes: NBD-N3 (A), 2NBD-N5 (B), NBD-N5NH (C), first (D), second (E) and fourth (F) fractions of NBD-LCPA. Dye concentration was $2 \mu \mathrm{M}$, calculating on NBD moieties (controlled with absorption at $498 \mathrm{~nm}$ ).

The NBD-LCPA dyes displayed their utility in the staining of diatomcontaining sediments (Fig. 9). Fluorescence microscopy allowed the siliceous valves to be distinguished from terrigenous components of the sediments. Staining of the diatom valves with fluorescent dyes allows studies to be performed with confocal microscopy (Fig. 10), including 3D-reconstruction of the valve morphology. 


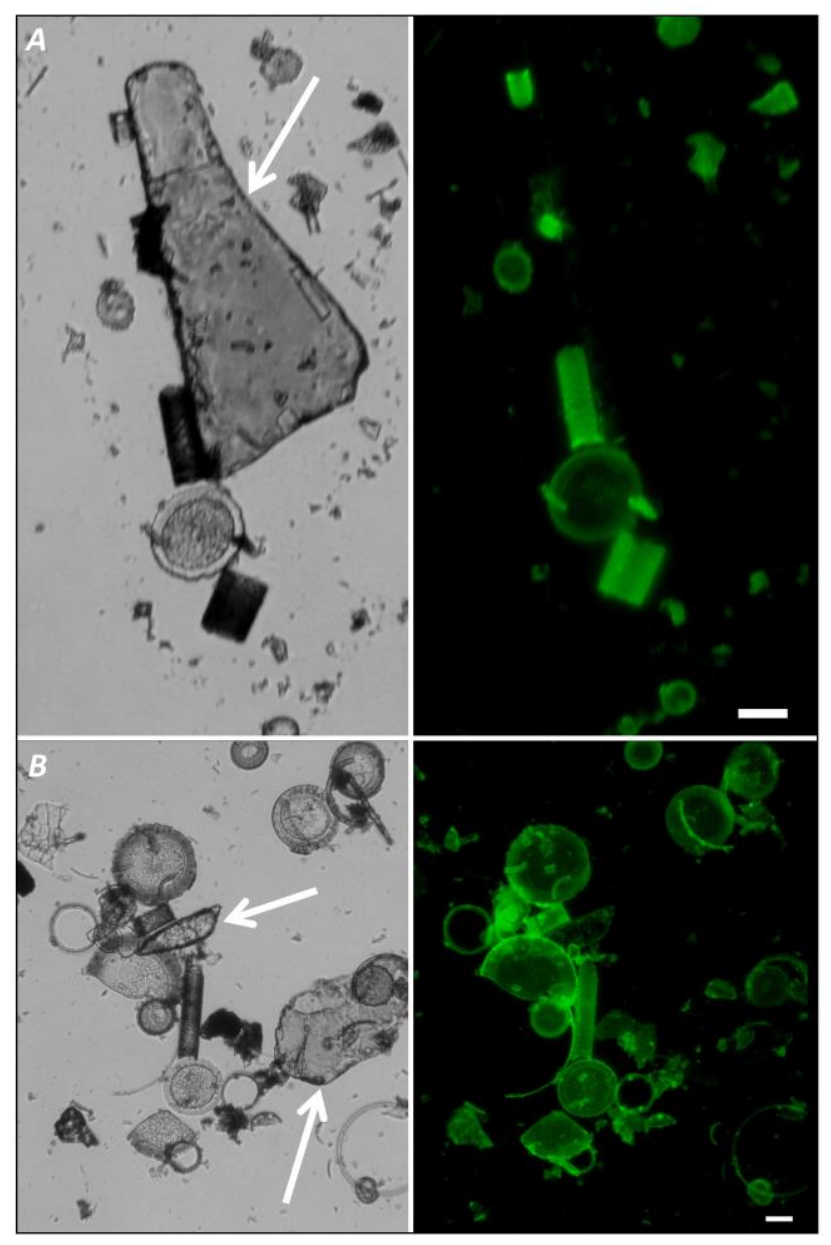

Figure 9. A and B staining of the Baikal sediments with first fraction of NBDLCPA dye ( $2 \mu \mathrm{M}$ solution). Arrows indicate the terrigenous components of the sediment. Scale bar represents $20 \mu \mathrm{m}$. 


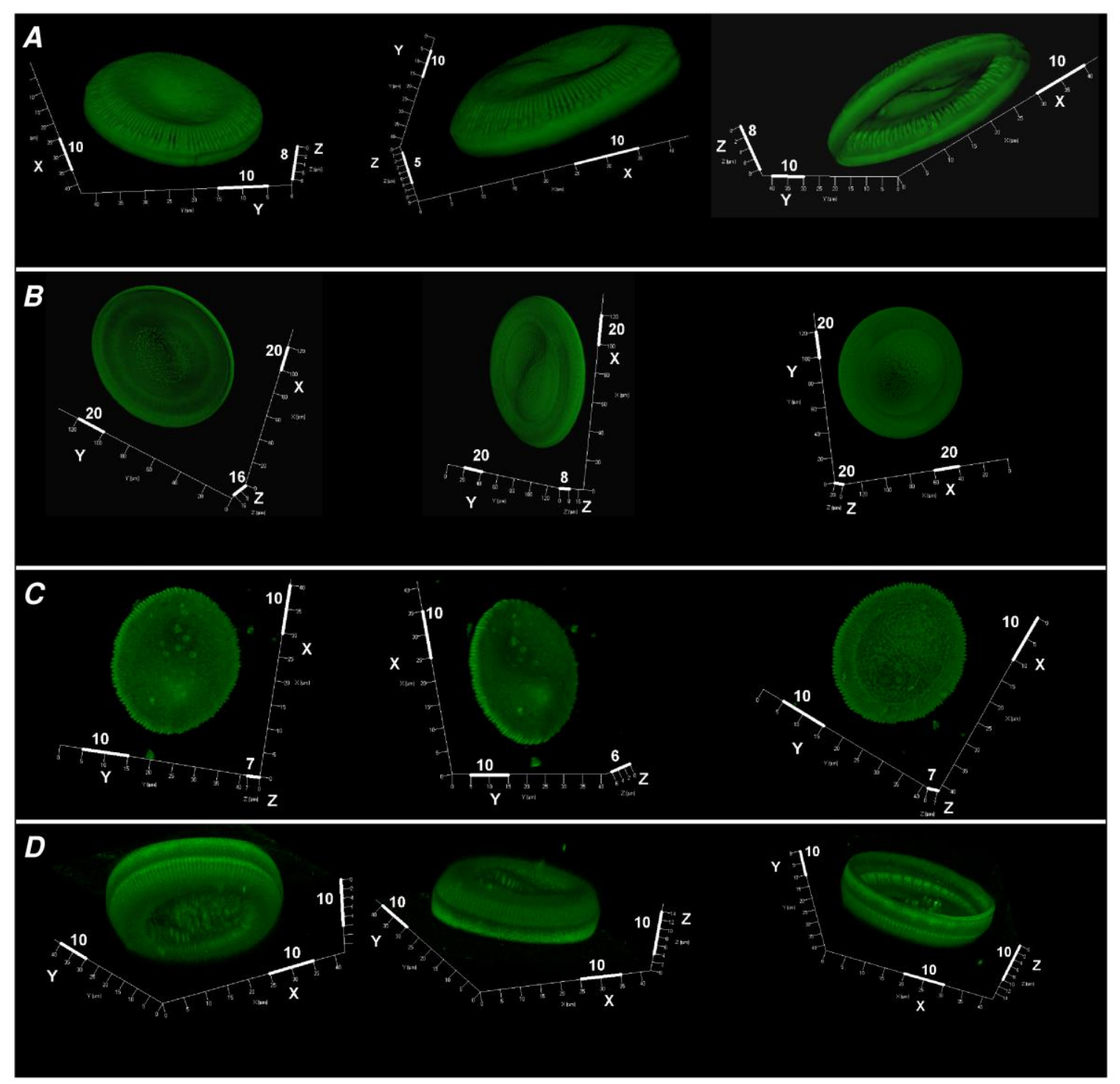

Figure 10. 3D reconstructions of the diatom valves. A and B - Cyclotella sp., $C$ and $D$ - samples from the Baikalean sediment. Scale bars are presented in $\mu \mathrm{m}$.

The fluorescently stained diatom valves can be applied as liquid flow tracers for hydrodynamic tests (Tauro et al., 2012; Hirano et al., 1999). The synthetic particles that are used in this area are compact particles of rounded or irregular shape. These particles show low hydrodynamic resistance and liquid can flow round them. Diatom valves are promising flow tracers because their high aspect ratio (low thickness compared with the other dimensions) and these valves may be more sensitive to small changes in the liquid flow. Particles in the liquid flow must be detected with some physical method and fluorescence allows this by an optical approach. Video files demonstrating the 
use of $U$. ferefusiformis valves stained with LCPA-NBD dye as liquid flow tracers are presented in the supplementary materials.

\section{Study of polyamine interaction with polymeric acids}

The physiological function of the polyamines in diatom algae is not clear. They were found in biosilica in a free state and grafted to silaffins - proteins with post-translation modifications including lysine residues linked with polyamines consisting of 5 or more propylamine units and phosphorylated hydroxyl-containing amino acids (Poulsen et al., 2003). Polyamines and silaffins are considered as the main components of the self-organizing matrix around which siliceous structures are formed (Sumper and Kroger, 2004) or as stabilizing agents for siliceous nanoparticles during silicon transport in the cytoplasm from the outer cell membrane to the silica deposition vesicle (Annenkov et al., 2011). Polyamines in both roles interact with polymers by mutual hydrogen and/or ionic bonds. These systems are known as intermacromolecular complexes (Tsuchida and Abe, 1982) and an important parameter which characterizes the ability of a polymeric substance to interact with other polymers, is the critical length of the interacting sequences above which the interaction is strong and almost independent of the length of the polymer. The synthesis and separation of NBD-tagged polyamines of various lengths allows the study of the critical length effects in polyamine - polymeric acid interactions. Mixing of fluorescent polyamine with polymeric acid results (Fig. 11, Fig. S1-5 in Supplementary Materials) in a change in the absorption spectra: absorption at $475-480 \mathrm{~nm}$ appears besides absorption at $490 \mathrm{~nm}$, which is characteristic for the NBD fragment. We studied the interaction of polyamines containing 1-8 amine units with poly (acrylic acid) (PAA), poly (methacrylic acid) (PMAA) and poly (vinyl phosphonic acid) (PVPA) at pH 3.510. Interaction between PAA and polyamines starts from NBD-N4 amine (three 
amine groups) and complexes are destroyed above pH 6.3 (NBD-N4), 6.5 (NBDN5) and 6.7 (NBD-N9). Complexes with PMAA are more stable, interaction starts from NBD-N3 and the $\mathrm{pH}$ of complex dissociation changes from 9 (NBDN3) to >10 (NBD-N5 and NBD-N9). The higher stability of PMAA complexes is usually explained as the stabilizing effect from the hydrophobic interactions of the methyl groups in PMAA units (Antipina et al., 1972). In the case of PVPA, the spectral manifestations of complexation are less evident than for carboxylic acids and PVPA-polyamine interactions were not visible at a $\mathrm{pH}$ higher than $5 . \mathrm{NaCl}$ addition to the polyamine-polymeric acid complexes destroys complexes at concentrations above $0.2 \mathrm{M}$ (Fig. S3 in Supplementary Materials) which is evidence that stabilization of the complexes is principally via electrostatic interactions.

The low activity of phosphate groups in interaction with polyamine chains contradicts an hypothesis (Sumper and Kroger, 2004) about the key role of such interactions in the formation of a supramolecular matrix for the condensation of silica precursors during biosynthesis of siliceous frustules in diatoms. On the one hand, the acidity of polymeric carbonic acids (PAA, PMAA, $\mathrm{pK}_{\mathrm{a}}=6-6.5$ (Katchalsky and Spitnik, 1947)) are close to poly (silicic acid) data $\left(\mathrm{pK}_{\mathrm{a}}=6-7\right.$ (Schindler and Kamber, 1968; Annenkov et al., 2017; Iler, 1979)). Taking into account possible pH values in cytoplasm (near 7) and in the Silicon Deposition Vesicles (SDV, 5.5 (Vrieling et al., 1999)), it is probable that free polyamines and polyamine side chains in silaffins can readily interact with oligosilicates and siliceous nanoparticles. These interactions can stabilize silica precursors on the way through the cytoplasm to the SDV and this stabilization can also facilitate $\mathrm{Si}(\mathrm{OH})_{4}$ capture from the environment by decreasing the intercellular concentration of monomeric silicic acid. 


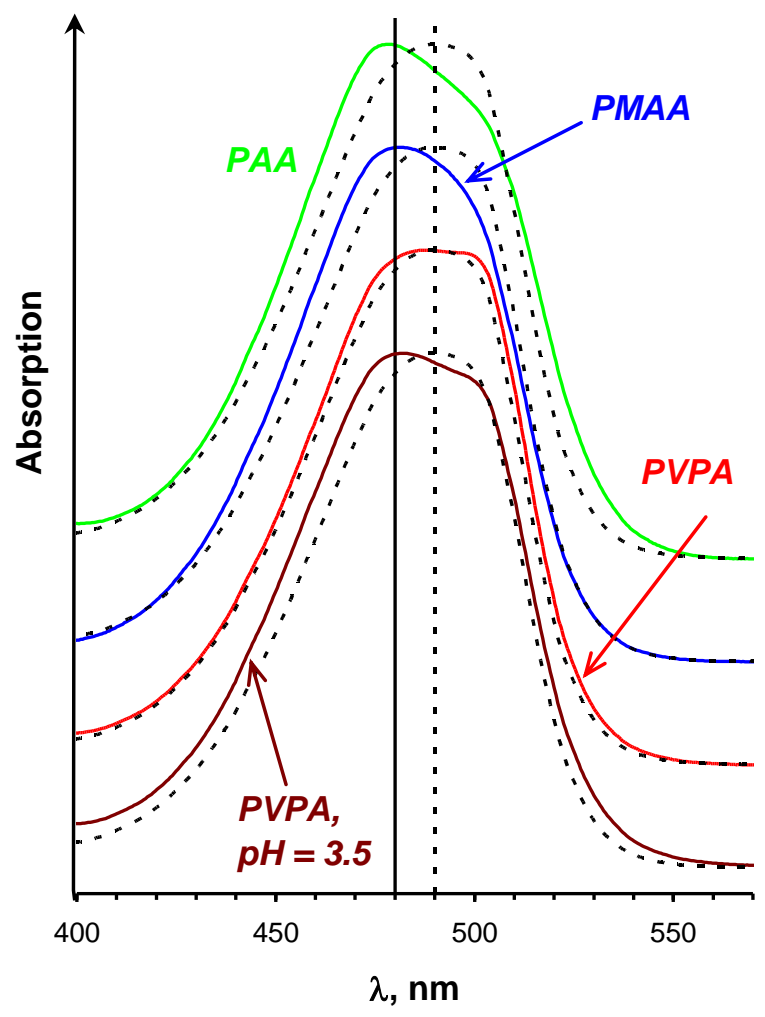

Figure 11. Visible spectra of NBD-N9 complexes with polymeric acids at pH 5. NBD-N9 concentration is $0.03 \mathrm{mM}$, polymeric acids - $5 \mathrm{mM}$. Dotted black lines correspond to blank solutions without polymeric acid.

\section{Conclusions}

We have synthesized new fluorescent dyes comprised of a long polyamine chain (6-18 nitrogen atoms) and an NBD fluorescent component. The dyes can be generated as oligomer mixtures and as individual compounds after HPLC separation. These new dyes are promising for the staining of various siliceous materials, e.g. valves of diatom algae, including fossilized samples from sediments. The long polyamine chain increases the dyes affinity to silica compared with previously described dyes based on polyamines containing five nitrogen atoms. The fluorescently stained diatom valves may be applied as liquid flow tracers in hydrodynamic tests. Study of the polyamine complexes with polymeric acids shows low stability of the complexes with poly 
(vinyl phosphonic acid) at a pH above 5 which corresponds to the conditions under which biogenic silica is thought to form in diatoms. The low activity of phosphate containing polymers in interaction with polyamines is a reason to reconsider the hypothesis concerning the role of a polyamine - polymeric phosphate matrix in biosilicification.

\section{Disclosure statement}

There are no conflicts of interest to disclose.

\section{Contributions}

Vadim V. Annenkov, Elena N. Danilovtseva, and Carole C. Perry conceived and designed the experiments, analyzed the data and wrote the manuscript. Olga N. Verkhozina and Graham J. Hickman performed experiments on synthesis, chromatography separation and mass-spectrometry analysis of the new compounds. Viktor A. Pal'shin was responsible for synthesis of poly (vinyl phosphonic acid) and microscopy experiments (together with

Olga N. Verkhozina). Tatyana A. Shishlyannikova did some mass-spectrometry experiments and studied (together with Elena N. Danilovtseva) interaction of the polyamines with polymeric acids. All of these authors reviewed the manuscript.

\section{Acknowledgements}

The study was partially supported by Project \# 16-04-00799a of the Russian Foundation for Basic Research and the Researcher Links Programme of the British Council (Olga Verkhozina). The Perry group are grateful for support from The Royal Society (Wolfson Research Merit award to CCP). We are thankful to the Center of Ultramicroanalysis (Limnological Institute) for 
providing equipment. We are deeply appreciative of Oleg Khlystov for the sample of Baikal sediment.

\section{References}

Annenkov, V.V., Patwardhan, S.V., Belton, D., Danilovtseva, E.N., Perry, C.C., 2006. A new stepwise synthesis of a family of propylamines derived from diatom silaffins and their activity in silicification. Chem. Commun. 14, 1521-1523.

Annenkov, V.V., Zelinskiy, S.N., Danilovtseva, E.N., Perry, C.C., 2009. Synthesis of biomimetic polyamines. ARKIVOC xiii, 116-130.

Annenkov, V.V., Danilovtseva, E.N., Zelinskiy, S.N., Basharina, T.N., Safonova, T.A., Korneva, E.S., Likhoshway, Y.V., Grachev, M.A., 2010. Novel fluorescent dyes based on oligopropylamines for the in vivo staining of eukaryotic unicellular algae. Anal. Biochem. 407, 44-51.

Annenkov, V.V., Danilovtseva, E.N., Pal'shin, V.A., Aseyev, V.O., Petrov, A.K., Kozlov, A.S., Patwardhan, S.V., Perry, C.C., 2011. Poly (vinyl amine) - silica composite nanoparticles: models of the silicic acid cytoplasmic pool and as a silica precursor for composite materials formation. Biomacromolecules 12, 1772-1780.

Annenkov, V.V., Glyzina, O.Yu., Verkhozina, O.N., Danilovtseva, E.N., 2014. Fluorescent amines as a new tool for study of siliceous sponges. Silicon 6 , 227-231.

Annenkov, V.V., Verkhozina, O.N., Shishlyannikova, T.A., Danilovtseva, E.N., 2015. Application of 4-chloro-7-nitrobenzo-2-oxa-1,3-diazole in analysis: fluorescent dyes and unexpected reaction with tertiary amines. Anal. Biochem. 486, 5-13. 
Annenkov, V.V., Danilovtseva, E.N., Pal'shin, V.A., Verkhozina, O.N., Zelinskiy, S.N., Krishnan, U.M., 2017. Silicic acid condensation under the influence of water-soluble polymers: from biology to new materials. RSC Adv. 7, 20995-21027.

Antipina, D., Baranovskii, V.Yu., Papisov, I.M., Kabanov, V.A., 1972. Equilibrium peculiarities in the complexing of polymeric acids with poly (ethylene glycols). Polym. Sci. U.S.S.R. 14, 1047-1057.

Armbrust, E.V., 2009. The life of diatoms in the world's oceans. Nature 459, 185-192.

Belton, D., Patwardhan, S.V., Annenkov, V.V., Danilovtseva, E.N., Perry, C.C., 2008. From biosilicification to novel mat erials: optimizing hydrophobic domains and resistance to protonation of polyamines. Proc. Natl. Acad. Sci. U.S.A. 105, 5963-5968.

Bridoux, M.C., Ingalls, A.E., 2010. Structural identification of long-chain polyamines associated with diatom biosilica in a Southern Ocean sediment core. Geochim. Cosmochim. Acta 74, 4044-4057.

Buruiana, E.C., Buruiana, T., Hahui, L., 2007. Preparation and characterization of new optically active poly(N-acryloyl chloride) functionalized with (S)phenylalanine and pendant pyrene. J. Photochem. Photobiol. A 189, 6572.

Danilovtseva, E.N., Verkhozina, O.N., Zelinskiy, S.N., Ivanov, N.A., Tsiganov, P.Yu., Basharina, T.N., Annenkov, V.V., 2013. New fluorescent derivatives of oligopropylamines. ARKIVOC iii, 266-281.

Desclés, J., Vartanian, M., El Harrak, A., Quinet, M., Bremond, N., Sapriel, G., Bibette, J., Lopez, P.J., 2008. New tools for labeling silica in living diatoms. New Phytologist. 177, 822-829. 
Dolatabadi, J.E.N., de la Guardia, M., 2011. Applications of diatoms and silica nanotechnology in biosensing, drug and gene delivery, and formation of complex metal nanostructures. Trends Anal. Chem. 30, 1538-1548.

Friedrichs, L., 2013. A simple cleaning and fluorescent staining protocol for recent and fossil diatom frustules. Diatom Res. 28, 317-327.

Gordon, R., Losic, D., Tiffany, M.A., Nagy, S.S., Sterrenburg, F.A.S., 2009. The Glass menagerie: diatoms for novel applications in nanotechnology. Trends Biotechnol. 27, 116-127.

Grachev, M.A.,. Annenkov, V.V., Likhoshway, Y.V., 2008. Silicon nanotechnologies of pigmented heterokonts. BioEssays 30, 328-337.

Hakkinen, M.R., Keinanen, T.A., Vepsalainen, J., Khomutov, A.R., Alhonen, L., Janne, J., Auriola, S., 2007. Analysis of underivatized polyamines by reversed phase liquid chromatography with electrospray tandem mass spectrometry. J. Pharm. Biomed. Anal. 45, 625-634.

Hirano, A., Tsujishita, M., Ohnishi, H., Nishigaki, M., Ippommatsu, M., Tsurutani, T., 1999. Method of measuring fluid flow by analyzing the fluorescent emissions from tracer particles in the fluid. Patent US 5979245 A.

Iler, R., 1979. The Chemistry of Silica, Wiley, New York.

Katchalsky, A., Spitnik, P., 1947. Potentiometric titrations of polymethacrylic acid. J. Polym. Sci. 2, 432-446.

Kulikovskiy, M., Lange-Bertalot, H., Annenkova, N., Gusev, E., Kociolek, J.P., 2016. Morphological and molecular evidence support description of two new diatom species from the genus Ulnaria in Lake Baikal. Fottea 16, 3442. 
Millaruelo, M., Steinert, V., Komber, H., Klopsch, R., Voit, B., 2008. Synthesis of vinylphosphonic acid anhydrides and their copolymerization with vinylphosphonic acid. Macromol. Chem. Phys. 209, 366-374.

Newman, S., Krigbaum, W.R., Laugier, C., Flory, P.J., 1954. Molecular dimensions in relation to intrinsic viscositie. J. Polym. Sci. 14, 451-462.

Parambath, M., Hanley, Q.S., Martin-Martinez, F.J., Giesa, T., Buehler, M.J., Perry, C.C., 2016. The nature of the silicaphilic fluorescence of PDMPO, Phys. Chem. Chem. Phys. 18, 5938-5948.

Parkinson, J., Gordon, R., 1999, Beyond micromachining: the potential of diatoms, Trends Biotechnol. 17, 190-196.

Poulsen, N., Sumper, M., Kroger, N., 2003. Biosilica formation in diatoms: characterization of native silaffin-2 and its role in silica morphogenesis. Proc. Natl. Acad. Sci. U.S.A. 100, 12075-12080

Rosi, N.L., Thaxton, C.S., Mirkin, C.A., 2004. Control of nanoparticle assembly by using DNA-modified diatom templates. Angew. Chem. Int. Ed. 43, 5500 $-5503$.

Schindler, P., Kamber, H.R., 1968. Die acitat von silanol-gruppen. Helv. Chim. Acta $51,1781-1786$

Shimizu, K., Del Amo, Y., Brzezinski, M.A., Stucky, G.D., Morse, D.E., 2001. A novel fluorescent silica tracer for biological silicification studies. Chem. Biol. 8, 1051-1060.

Stevenson, R.J., Bothwell, M.L., Lowe R.L. (Eds.), 1996. Algal ecology: freshwater benthic ecosystems, Academic Press, San Diego.

Su, Y., Lundholm, N., Friis, S.M.M., Ellegaard, M., 2015. Implications for photonic applications of diatom growth and frustule nanostructure changes in response to different light wavelengths, Nano Res. 8, 23632372. 
Su, Y., Lenau, T.A., Gundersen, E., Kirkensgaard, J.J.K., Maibohm, C., Pinti, J., Ellegaard M., 2018. The UV filtering potential of dropcasted layers of frustules of three diatom species. Sci. Rep. 8, 1-10.

Sumper, M., Kroger, N., 2004. Silica formation in diatoms: the function of longchain polyamines and silaffins. J. Mater. Chem. 14, 2059-2065.

Sumper, M., Brunner, E., Lehmann, G., 2005. Biomineralization in diatoms: characterization of novel polyamines associated with silica. FEBS Lett. 579, 3765-3769.

Tauro, F., Grimaldi, S., Petroselli, A., Rulli, M.C., Porfiri, M., 2012. Fluorescent particle tracers in surface hydrology: a proof of concept in a semi-natural hillslope. Hydrol. Earth Syst. Sci. 16, 2973-2983.

Thompson, A.S., Rhodes, J.C., Pettman, I., 1988. Culture Collections of Algae and Protozoa: Catalogue of Strains, Titus Wilson, Kendal, UK.

Townley, H.E., Parker, A.R., White-Cooper, H., 2008. Exploitation of diatom frustules for nanotechnology: tethering active biomolecules. Adv. Funct. Mater. 18, 369-374

Treguer, P., Nelson, D.M., Van Bennekom, A.J., Demaster, D.J., Leynaert, A.B., 1995. The silica balance in the world ocean: a reestimate. Science 268, 375-379.

Tsuchida, E., Abe, K., 1982. Interactions Between macromolecules in solution and intermacromolecular complexes. Adv. Polym. Sci. 45, 15-130.

Vrieling, E.G., Gieskes, W.W.C., Beelen, T.P.M., 1999. Silicon deposition in diatoms: control by the $\mathrm{pH}$ inside the silicon deposition vesicle. J. Phycol. $35,548-559$. 